\title{
Tailoring of Self-Management Interventions in Patients With Heart Failure
}

\author{
Irene Bos-Touwen $^{1} \cdot$ Nini Jonkman ${ }^{1} \cdot$ Heleen Westland ${ }^{1} \cdot$ Marieke Schuurmans $^{1}$. \\ Frans Rutten ${ }^{2}$ - Niek de Wit $^{2}$ - Jaap Trappenburg ${ }^{1}$
}

Published online: 2 May 2015

(C) The Author(s) 2015. This article is published with open access at Springerlink.com

\begin{abstract}
The effectiveness of heart failure (HF) selfmanagement interventions varies within patients suggesting that one size does not fit all. It is expected that effectiveness can be optimized when interventions are tailored to individual patients. The aim of this review was to synthesize the literature on current use of tailoring in self-management interventions and patient characteristics associated with self-management capacity and success of interventions, as building blocks for tailoring. Within available trials, the degree to which interventions are explicitly tailored is marginal and often limited to content. We found that certain patient characteristics that are
\end{abstract}

This article is part of the Topical Collection on Self-Care and Health outcomes

Jaap Trappenburg

J.Trappen@umcutrecht.nl

Irene Bos-Touwen

i.d.touwen-3@umcutrecht.nl

Nini Jonkman

N.Jonkman@umcutrecht.nl

Heleen Westland

H.Westland@umcutrecht.nl

Marieke Schuurmans

M.J.Schuurmans@umcutrecht.nl

Frans Rutten

F.H.Rutten@umcutrecht.nl

Niek de Wit

N.J.deWit@umcutrecht.nl

1 Department Rehabilitation, Nursing Science \& Sports, University Medical Center Utrecht, PO Box 85500, 3508

GA Utrecht, The Netherlands

2 Julius Center, Department of General Practice, University Medical Center Utrecht, PO Box 85500, 3508 GA Utrecht, The Netherlands associated with poor self-management capacity do not influence effectiveness of a given intervention (i.e., age, gender, ethnicity, disease severity, number of comorbidities) and that other characteristics (low: income, literacy, education, baseline self-management capacity) in fact are indicators of patients with a high likelihood for success. Increased scientific efforts are needed to continue unraveling success of selfmanagement interventions and to validate the modifying impact of currently known patient characteristics.

Keywords Heart failure · Self-management interventions · Tailoring $\cdot$ Patient characteristics

\section{Introduction}

Heart failure (HF) is a major health problem [1, 2], characterized by a wide spectrum of debilitating symptoms, poor quality of life, frequent hospitalizations, and high mortality [3, 4]. Outcomes have improved over the last two decades for those with $\mathrm{HF}$ and a reduced ejection fraction with pharmacological therapy, devices, and multidisciplinary management programs $[3,5]$.

A part of the progression of HF and its burden on patients and society is thought to be preventable if patients are engaged in the (proactive) management of their disease [6, 7]. Patients who are actively involved in their care and who have the competences to adhere to treatment regimens and take appropriate actions are expected to have better survival and reduced hospital (re-)admissions [8-10]. In the literature, the terms self-management, self-maintenance, and self-care sometimes are used as separate terms [11] and sometimes used interchangeably to cover the complex challenges patients face in coping with their disease [12]. To enhance the readability and to remain consistent with international chronic care models 
[13], we will use the term self-management throughout this review. The key targeted HF self-management competences are (i) adherence to complex medication regimens, (ii) monitoring symptoms and taking appropriate action when needed, and (iii) compliance with exercise, dietary, and other lifestyle recommendations [14].

Over the past decades, many interventions have been developed and evaluated that may help to equip patients with these complex self-management competences. Most interventions provided (nurse-led) patient education and training skills to support self-management [15]. Several meta-analyses have highlighted the heterogeneity in delivery, methods, and duration of these interventions. Reviews including studies that evaluated isolated educational interventions showed improvements in knowledge [16, 17]. When self-management was studied as part of more comprehensive disease-management or telehealth program, more robust results were reported, such as reduction of disease-related hospital admissions [18-23], mortality $[18,19,22]$, and improved health-related quality of life (HRQoL) [24]. One meta-analysis calculated the pooled results of isolated self-management interventions and found a reduction in HF and all-cause hospitalizations and improved medication adherence but not in mortality, HRQoL, functional capacity, or symptoms [25]. The results from the aforementioned reviews indicate that the evidence for effectiveness of self-management interventions is ambiguous. This may be partly due to mixed quality of the reviews [26], heterogeneity in program and patient characteristics [27], and low treatment fidelity of the provider [28].

There is a need to better understand the key elements of successful self-management interventions. An important starting point is recognizing that managing a complex multiimpact disease is difficult. This is supported by several studies showing that self-management capacity in patients with $\mathrm{HF}$ is generally poor [29-32]. Pooled results from 15 countries indicated that poor uptake of self-management is a worldwide phenomenon [33••]. Besides variations in self-management capacity, longitudinal studies have shown that patientspecific characteristics also seem to modify the effectiveness of self-management interventions. Meta-analytical findings have indicated that a substantial number of patients do not or insufficiently respond to self-management interventions $[25$, 34]. The current premise that some interventions work better in specific patient populations and not in others suggest that one size does not fit all [27, 35•]: in other words, more tailored approaches will be needed.

In a tailored approach, the treatment exposure is dynamic instead of the more fixed exposure in one-size-fits-all interventions [36]. In a tailored intervention, the individual is assessed and the intervention is customized based on the unique characteristics of that person, in order to increase the relevance of treatment and to produce greater desired changes [37]. Customization refers to the personalized treatment consequence, such as variations in content (topics), behavior change techniques, mode of delivery, and dose [38]. A specific type of tailoring is targeting in which subgroup characteristics are used to develop a single intervention for a defined population subgroup [36].

To optimize tailoring of interventions in $\mathrm{HF}$, a thorough understanding of effective intervention ingredients is required, as well as knowledge of tailoring strategies and subgroups of patients in which a given self-management intervention is most effective. The aims of this review are (1) to describe the current use of tailoring in self-management interventions in patients with $\mathrm{HF}$ and to synthesize the essential literature on patient characteristics associated with (2) self-management capacity and (3) intervention effects.

\section{Current Use of Tailored Self-Management Approaches in Clinical Trials}

Recently, we established a large international collaboration between principal investigators of HF self-management trials [35•]. The aim of this consortium is to unravel success of selfmanagement interventions through pooling and modeling individual patient data (IPD) in a meta-analysis of previously conducted randomized clinical trials. The search and selection strategy applied in the IPD meta-analysis has been described in detail elsewhere [35•]. Self-management interventions were operationalized as patient-focused interventions with at least two of the following components: (1) active stimulation of symptom monitoring, (2) education in problem solving skills (i.e., self-treatment such as managing acute exacerbations, resource utilization, and stress/symptom management), and enhancement of either (3) medication adherence, (4) physical activity, (5) dietary intake, or (6) smoking cessation. For this review, we used a similar search strategy of the ongoing IPD meta-analysis and updated the study selection (until January 2015) [35•].

Data on presence and type of tailoring were extracted for 52 self-management interventions. Tailoring was considered present if the intervention was personalized, and based on an assessment of individual characteristics. Table 1 provides an overview of the tailoring strategies in HF self-management interventions and the theory underlying the tailored intervention. Of the 52 selected studies, 28 explicitly described their tailoring strategy. The sample size of the studies ranged from 40 to 715 , and the majority were nurse-led interventions. Studies not included in Table 1 were either not tailored or the investigators did not explicitly report their tailoring strategy [39-45, 46••, 47-62]. This includes studies in which the content might have been individualized to some extent but no clear description was provided on how this was applied. For example, in interventions with face-to-face consultations, interpersonal communication, goal setting, and problem solving 


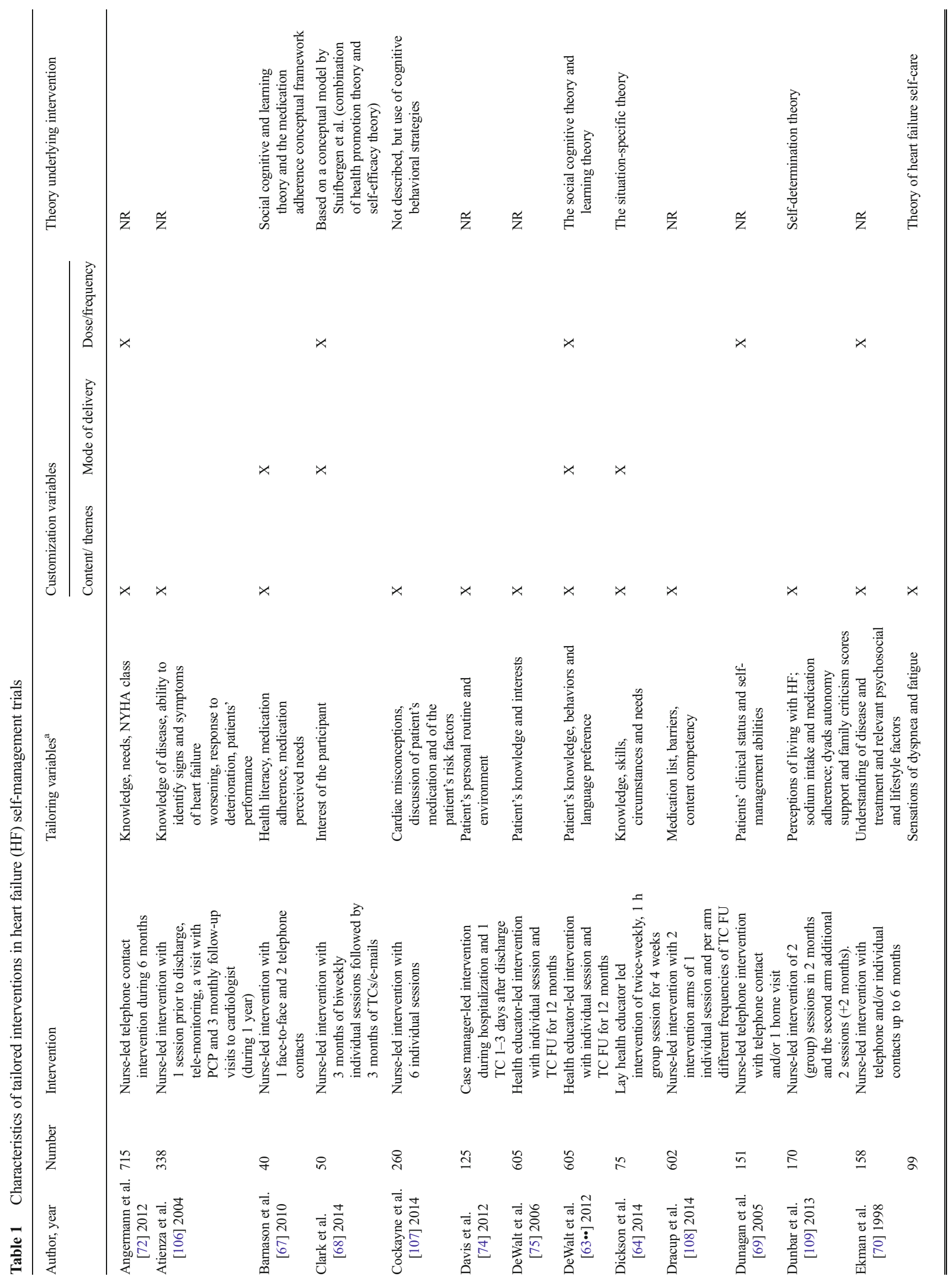




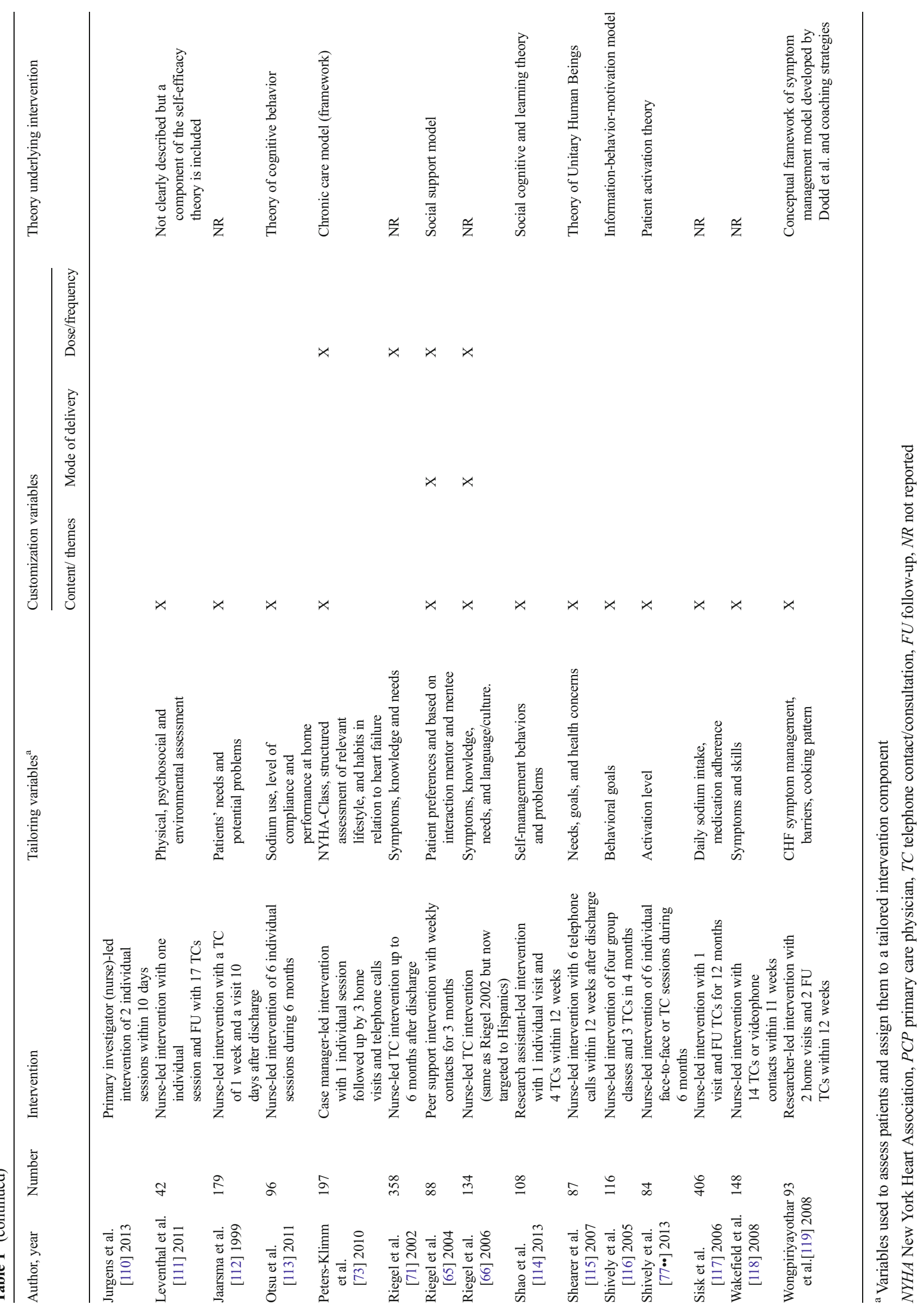


could have resulted in individualization of the intervention, but this was not clearly reported in the publication.

\section{Tailoring Strategies}

The 28 studies included a wide range of patient characteristics which guided tailoring of the content, dose, or mode of the intervention. The most frequently mentioned were HF-related knowledge, self-management behaviors/skills (such as medication adherence, sodium intake, identify symptoms of deterioration, problem solving), barriers for self-management, and patient-reported needs and preferences. Other variables mentioned were environmental factors, health literacy, New York Heart Association (NYHA) class, and activation level.

Tailoring was applied mostly with regard to content, thus addressing different topics based on the assessed patient characteristics. Six interventions customized on the mode of delivery, either changing the language $[63 \bullet \cdot, 64-66]$ or adapting the literacy level [67], and one study gave a choice in telephone or e-mail contact [68]. Nine interventions varied contact frequency based on needs [66, 69-71], NYHA-class [72, 73], or patients' preference [63・•, 65, 68]. None of the studies reported on tailoring with regard to behavior change techniques.

We found five studies with an intervention designed for and targeted to a specific subgroup. Davis et al. targeted the intervention to HF patients with mild cognitive impairment by focusing on environmental manipulation (e.g., simplifying tasks) and training compensatory strategies (e.g., memory aids) [74]. Barnason et al. targeted their intervention to HF patients at risk for impaired medication adherence (five or more routinely scheduled prescriptions) [67]. Riegel et al. [66] adjusted a previous intervention to Hispanics by integrating cultural values and the possibility of bilingual support. In two subsequent studies, DeWalt et al. targeted their intervention to low literate patients, where the intervention was not only given to the subgroup of low literates but to all HF patients included in the trial $[63 \bullet \bullet, 75]$.

\section{Theoretical Models Underlying Tailored Interventions}

In 14 of the tailored interventions, theoretical models were used as the underlying mechanism of the intervention. Most often Bandura's social cognitive theory was used, particularly aiming at increasing patients' self-efficacy [76]. In one single study, a theoretical model was explicitly used for tailoring. Shively et al. used the activation theory to tailor the intervention based on patients' initial activation level as measured by the Patient Activation Measure (PAM) [77••]. Patients' baseline level of activation was assessed as low or medium to high and subsequently individualized goals were set for knowledge (low PAM) or skills and behaviors (medium and high PAM) $[77 \bullet \bullet]$.

\section{Patient Characteristics Associated With Self-Management Capacity}

A large number of cross-sectional studies have evaluated the association between patient characteristics and varying selfmanagement capacity to identify patients at risk for poor selfmanagement capacity. Although not exhaustive, a summary of the most important identified characteristics is provided below.

In the early 1990s, Connely et al. already developed a conceptual model to increase the understanding of varying selfmanagement capacity, the Model of Self-Care in Chronic Illness (MSSCI) [78]. In chronic disease patients, gender, age, income, education, social support, symptom severity, and comorbidities were initially identified as determinants of selfmanagement capacity [78]. The determinants hypothesized in the MSSCI have been tested in multiple HF populations with relatively inconsistent findings. Rockwell et al. found level of education and symptom severity to explain $10.3 \%$ of the variance in self-management capacity [79]. A subsequent study could not replicate these findings but found that males and patients with less comorbidities were more likely to be good self-managers [30]. Partly similar findings were found by Cameron et al. where older age, male gender, comorbidities, and depression were associated with poor selfmanagement capacity [31]. The association with depression [80] and poor self-management capacity has been replicated in several studies [32, 81]. Besides depression, anxiety and cognitive dysfunction are highly prevalent in patients with $\mathrm{HF}$ and seem to complicate engagement in self-management $[32,82$, 83]. Performance in self-management also seems to be influenced by experience. Two studies have investigated the relation between the time from diagnosis and showed better scores for experienced patients on self-care maintenance and selfcare management scores but surprisingly not on self-care confidence [84, 85]. Other important characteristics that have shown to hamper self-management behaviors in HF are both low literacy and low health literacy. For patients with inadequate literacy, it is more difficult to understand health information and act upon it to perform good self-management [86]. For low health literacy, several studies found it to be independently associated with poor self-management capacity [87-89].

Alongside designating patients with a higher likelihood for poor self-management capacity, decision making on tailored strategies might also be served by getting an in-depth understanding of varying self-management behaviors. Meanwhile, two recent meta-syntheses have been conducted, synthesizing results from a large number of qualitative studies aimed at increasing our understanding on varying self-management capacity $[90 \bullet, 91 \bullet]$. The first included 23 studies indicated that disease severity, limited knowledge, comorbidities, cognitive and emotional dysfunction, communication skills, and 
adverse coping strategies were barriers for adequate selfmanagement capacity. Facilitators were social support, disavowal (healthy denial) coping strategy, trust in health care providers, spiritual beliefs, and optimism [90•]. The most recent meta-synthesis mainly focused on the impact of different contextual factors and included 45 studies. Strachan et al. identified six main types of contextual factors to complicate self-management in HF patients: lack and overload of caregiver support (usually family members), limited social networks, living in rural areas, limited financial capacity, and limited interaction with peers [91•].

Summarizing the great efforts that have been made, we can draw a tentative conclusion that age, gender, (health) literacy, socio-economic class, comorbidities, and emotional and cognitive function are key recurring patient characteristics that are associated with self-management capacity. It is appealing to assume that results from cross-sectional studies might help us to guide targeting or tailoring interventions. Yet, factors associated with self-management capacity are not necessarily those with a higher likelihood for success of selfmanagement interventions. The cross-sectional nature of these studies only provide a snapshot of the association at one time point and give no indication of causal mechanism occurring over time initiated by an intervention.

\section{Patient Characteristics Associated With Success of a Given Intervention}

In contrast to cross-sectional analyses which solely allow for the identification of characteristics associated with selfmanagement capacity, decision making on tailoring can be facilitated by unraveling success of self-management interventions. Quantifying in whom a given intervention is most likely to be successful can be analyzed by identification of effect modification [92, 93]. Effect modification is defined as the difference in the association between the treatment and outcome across different subgroups of patients [94].

Effect modifiers can be identified by stratified analysis where the association between the intervention and outcome is reported for each level of a baseline characteristic. Differences in this association suggest the presence of effect modification [95]. Another method is the measurement of statistical interaction, whereby the statistical significant contribution of the product term between treatment exposure and the baseline characteristic indicates effect modification [94]. To identify patient characteristics modifying success of HF selfmanagement interventions, we could again rely on the selection of randomized trials as reported in the previous section.

Table 2 shows the results of studies evaluating effect modification including the type of analysis and included baseline variables. From the 52 interventions, 12 analyzed the presence of effect modification. The majority focused on demographic variables. None of the studies found differences in success of self-management interventions across different levels of age $[40,42,50,63 \cdot \bullet, 96 \bullet \cdot]$ or race $[50,63 \bullet \bullet, 96 \bullet \cdot]$. This finding is in contrast to well-established associations between these characteristics and self-management capacity. The same accounts for gender differences except for Mårtensson et al. who found subtle gender-specific differences in effectiveness of a nurse-led self-management intervention on SF-36 subscales in the advantage of women [56]. In an additional analysis on self-management behaviors, they showed this could have been mediated by women having a higher tendency to improve adherence to daily weight control [97]. Two separate studies evaluated effect modification in the HART trial and evaluated the impact of low socio-economic class. Although not associated with change in HRQoL [63・•], low-income patients (annual family income of $<\$ 30,000$ ) receiving a self-management intervention had $44 \%$ longer time to hospitalization or death compared to low-income patients receiving education only [50]. The same direction of association is seen for level of education. Although previous cross-sectional studies (incl. qualitative studies) have shown that low education is associated with poor self-management capacity, additional analysis nested in a large Dutch trial [57] indicates that in fact this group might particularly benefit from the widely validated Chronic Disease Self-Management Program (CDSMP) [98]. The authors found that patients attended $<12$ years of education gained more improvements in HRQoL compared to their higher educated counterparts. In the same study, cognitive function was identified as an effect modifier of success of CDSMP too, favoring those with a higher baseline cognitive status [98]. The impact of low literacy on success of selfmanagement interventions has been thoroughly investigated by DeWalt and colleagues. Initially, in a relatively small single-center RCT, this research group evaluated the effectiveness of a literacy-sensitive intervention. Although statistically underpowered, they performed a stratified analysis within two levels of baseline literacy and found no indications for effect modification [75]. In a subsequent larger trial $(n=605)$, they examined the difference in effectiveness between a singlesession self-management intervention and additional telephonic reinforcement. They reported the impact of age, sex, education, income, ethnicity, NYHA class and literacy, and change in several outcome measures. Only literacy was identified as an effect modifier of the extensive intervention. While emphasized in many studies as a factor hindering successful self-management behavior, having a baseline low/marginal literacy was associated with a higher likelihood for success both in HRQoL [99] and number of hospitalizations [63・•].

Five studies $[40,50,57,63 \bullet \bullet, 96 \bullet \bullet]$ evaluated the effectiveness of self-management intervention within strata of HFspecific characteristics such as severity (NYHA class, ejection fraction, time from diagnosis) and ischemic etiology. Only Bocchi et al. found that in patients with baseline NYHA I- 


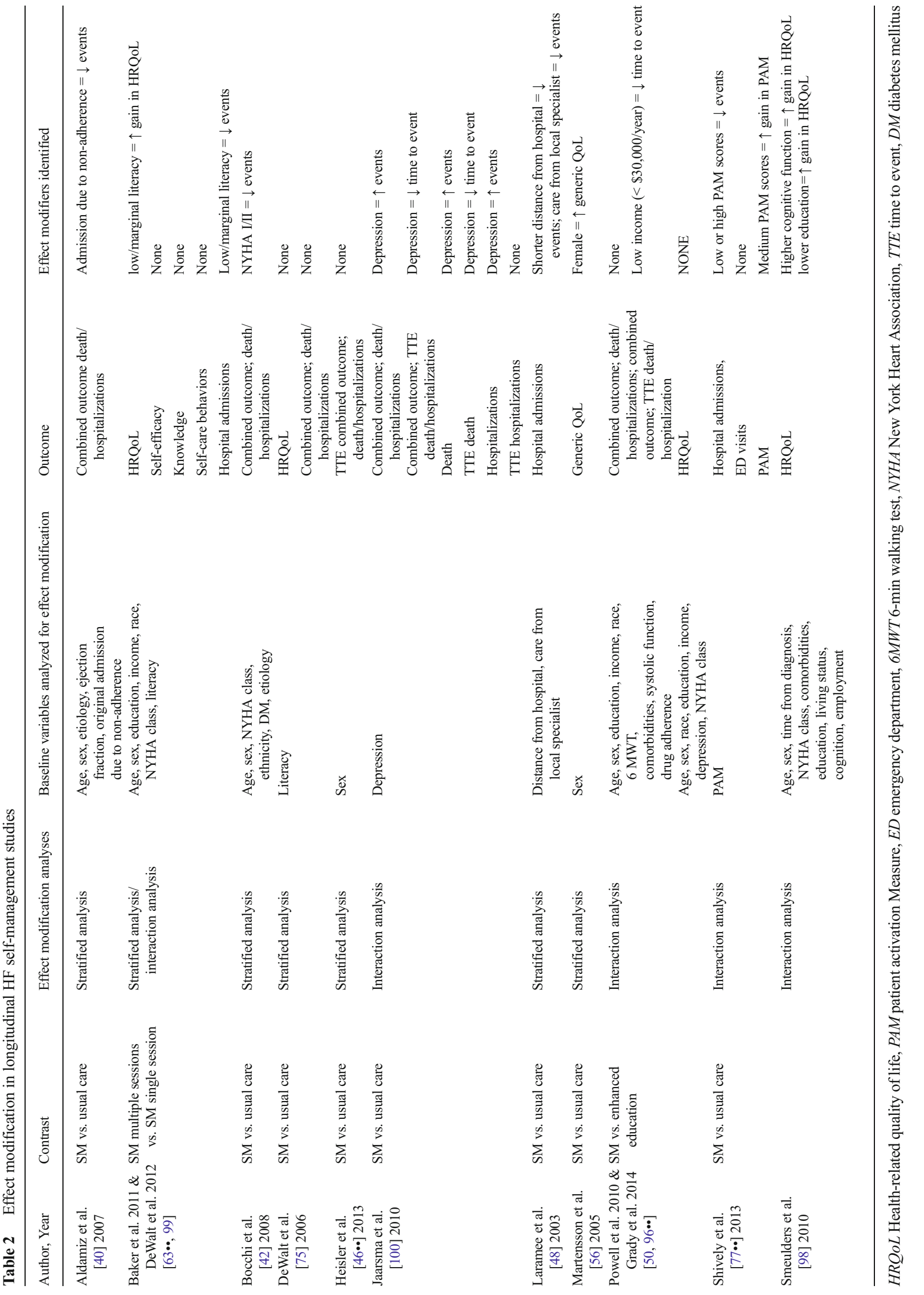


II, a program with repetitive education and telephone monitoring resulted in a larger risk reduction on the composite outcome hospitalization or death [42].

As a reflection of disease complexity, two studies have evaluated the impact of comorbidities. Although operationalization of comorbidities varied, no indications for effect modification were observed [50, 57]. Yet, specific comorbidities do seem to hinder the success of self-management. In addition to the negative influence of low cognitive function, as indicated earlier, baseline depression might also lead to less successful outcomes of self-management interventions. While no effect modification was identified for HRQoL in the HART trial [96*•], interaction analysis in the $\mathrm{COACH}$ trial showed that the intervention was only effective on time to death/readmission and reduced mortality rates in patients without depression [100].

Few studies have analyzed whether baseline selfmanagement competences can influence success of interventions. One might assume that the initial level of HF-specific self-management behaviors and known mediators of change in self-management capacity such as self-efficacy and activation determine the didactic room for improvement. This is supported by the interaction analysis nested in a Spanish RCT where they analyzed a broad range of potential effect modifiers. In a subgroup of patients whose original admission was attributed to non-adherence, the risk reduction for combined readmission or death rate was significantly greater [40]. Shively et al. studied the impact of baseline levels of activation, as measured by the PAM on success of a selfmanagement intervention [77••]. Their results indicated that moderately activated patients were the ones with the highest likelihood for a positive change in the PAM, while in low and highly activated patients, the intervention resulted in a higher reduction in hospitalizations. Interpretation of these results is complicated by the fact that the intervention was tailored based on patients' initial level of activation [77••].

In summary, age, ethnicity, gender, number of comorbidities, and disease severity do not seem to influence the success of self-management interventions. Low education, low income, low literacy, and low baseline self-management capacity seem to facilitate success, while depression and cognitive dysfunction seem to hinder success of self-management interventions.

\section{Clinical Implications}

To curb the complexity of HF and to reduce its impact on patients and society, a multi-faceted approach is needed, in which patients have an important responsibility in determining the course of their disease. Improved self-management capacity contributes to better HF-related outcomes and reduction in hospitalizations and mortality. Interventions aimed at supporting patients in increasing these competences have shown to be successful, however, not in all patients. To optimize effectiveness of those interventions prompts the use of better targeted or tailored interventions. It is likely that adaptive interventions, combining the identification of certain subgroups and subsequent tailored solutions will result in higher effect sizes. However, within the large number of available trials, the degree to which interventions are explicitly tailored is marginal.

For future interventions and to support clinical practice, we have summarized the results of many scientific efforts to identify patient characteristics that are clinically relevant to guide targeting and tailoring. For age, gender, ethnicity, disease severity, and number of comorbidities, substantial evidence is available that these factors do not seem to influence the degree of success of self-management interventions. Other characteristics initially identified as factors potentially hindering effective self-management in longitudinal studies are in fact indicators of those patients with the highest likelihood for improvement. Knowledge of these effect modifiers gives rise to formally include these factors in the screening process, especially when more efficient allocation of resources is indicated. Patients with low literacy, low education, and low income at baseline have shown to be suitable candidates for selfmanagement support. It can be expected that more tailored approaches can even further boost effect sizes (e.g., (health) literacy sensitive interventions). Effective guidelines are available to provide patients with additional support, adapt communication strategies, and educational content and materials $[86,101]$. Low-income patients already seem to benefit from current self-management interventions, yet policy-makers should stay vigilant to prevent financial factors from hindering the effects of self-management.

Another important aspect is the baseline assessment of selfmanagement capacity including important mediators of behavior change such as self-efficacy, knowledge, adherence, and activation. A limited number of studies indicate that initial poor self-management behaviors do not hinder but instead represent those with a high didactic potential for improvement.

Current evidence of effect modification in clinical trials indicates that certain characteristics do hamper the likelihood for success of self-management interventions. Cognitive dysfunction and depression are highly prevalent comorbidities in $\mathrm{HF}$, and both seem to have negative impact on the effectiveness of self-management interventions. Therefore, formal screening at baseline for these factors is imperative. For cognitive dysfunction, both learning and subsequently performing self-management are highly challenging. In current available trials, interventions seldom formally screen for cognition and do not seem to be sensitive in sufficiently tackling the influence of cognition on increasing self-management competences. It seems sensible that interventions in this 
subgroup of patients need to be extended with increased assistance, allocation of caregivers, cognitive training, and environmental manipulations, i.e., by simplifying tasks, providing external cues, or prompts to initiate action [74]. Given the high prevalence in the HF population, the impact of depression on success of self-management is disturbing. Although little evidence is available on tailored strategies in this subgroup, it seems useful to incorporate screening of depressive symptoms at enrollment and to consider cognitive behavioral therapy or to add antidepressants [102].

\section{Research Implications}

Extensive scientific work has been done to increase our understanding in whom self-management is problematic and in whom self-management interventions are most effective. Yet, the interplay between patient characteristics, self-management capacity, and the likelihood for success of interventions is still unclear. In our quest to establish tailored HF self-management, we should slowly abandon from cross-sectional analyses, since many studies already have been performed, and they have provided limited information on the causal mechanisms towards success. Instead, decision making on tailored strategies is served by comprehensive identification of effect modifiers from longitudinal studies.

Understanding the variance in effectiveness among subgroups is complicated by the heterogeneity in available intervention strategies. Substantial variations in intervention components, mode of delivery, and dose hamper answering "what works in whom," the key towards effective tailoring of future interventions. Increased scientific efforts are needed to validate the modifying impact of currently known characteristics such as (health) literacy, education, income, cognitive, and emotional status across different treatment strategies. In addition, more knowledge is needed on the extent to which initial self-management capacity and levels of key baseline behavioral mediators reflect the potential for improvement. Stratified analysis in well-powered randomized trials, preferably with multiple treatment arms, can help us to further unravel the causal mechanism between patient and intervention characteristics. Additionally, data from longitudinal routine-care cohorts and an ongoing Individual Patient Data metaanalysis [35•] can help us to untangle success of selfmanagement as a bridge towards more individually tailored strategies.

Available trials on HF self-management have not always clearly described how tailoring was applied. The minority of studies which explicitly described the tailoring strategy generally limited tailoring to individualizing content. Guided by the accumulating knowledge in this field, future studies are needed to study the added value of tailoring interventions in terms of behavioral change techniques [103], mode of delivery (i.e., regular consultations vs. e-Health solutions), and intensity. A promising design to this purpose is the use of adaptive interventions designs, whereby the type or dosage of the intervention is adapted based on patient characteristics and the treatment is adjusted repeatedly over time [104]. These interventions use individual differences between participants to achieve the best possible outcome, both by augmenting an intervention for a non-responsive participant or diminishing treatment for a responsive participant in order to reduce cost or participant burden. Sequential, multiple assignments, randomized trials (SMART) can be used to test the decision rules for an adaptive intervention [105].

\section{Conclusion}

Although embedded in HF guidelines, effectiveness of selfmanagement interventions has not yet reached its full potential. Effectiveness can be substantially optimized when interventions are better tailored to individual patients. Currently, available trials did individualize the intervention to a certain extent; however, this was rarely applied through explicit identification of certain subgroups and subsequent provision of tailored solutions. In this review, we synthesized essential literature which can serve as building blocks for future development of tailored self-management approaches. The results show that we have to redirect our efforts: several characteristics previously considered to be associated with poor selfmanagement capacity (age, gender, ethnicity, disease severity, number of comorbidities) actually do not affect effectiveness of a given intervention. Other factors such as low income, low literacy, low educational level, and low baseline selfmanagement capacity in fact point at those patients with the largest potential for improvement. Identifying those patients with a high likelihood for success can increase effectiveness of interventions. Particular emphasis should be placed on proactive screening and attempts to develop and validate tailored strategies for patients with cognitive or emotional dysfunction. Meanwhile, scientific efforts are needed to unravel success of self-management interventions and the added value of tailoring.

\section{Compliance with Ethics Guidelines}

Conflict of Interest Irene Bos-Touwen, Nini Jonkman, Heleen Westland, Marieke Schuurmans, Frans Rutten, Niek de Wit, and Jaap Trappenburg declare that they have no conflict of interest.

Human and Animal Rights and Informed Consent This article does not contain any studies with human or animal subjects performed by any of the authors.

Open Access This article is distributed under the terms of the Creative Commons Attribution 4.0 International License (http:// 
creativecommons.org/licenses/by/4.0/), which permits unrestricted use, distribution, and reproduction in any medium, provided you give appropriate credit to the original author(s) and the source, provide a link to the Creative Commons license, and indicate if changes were made.

\section{References}

Papers of particular interest, published recently, have been highlighted as:

- Of importance

-• Of major importance

1. Mosterd A, Hoes AW. Clinical epidemiology of heart failure. Heart. 2007;93:1137-46.

2. Engelfriet PM, Hoogenveen RT, Boshuizen HC, van Baal PH. To die with or from heart failure: a difference that counts: is heart failure underrepresented in national mortality statistics? Eur J Heart Fail. 2011;13:377-83. doi:10.1093/eurjhf/hfq223.

3. McMurray JJ, Adamopoulos S, Anker SD, Auricchio A, Bohm M, Dickstein K, et al. ESC guidelines for the diagnosis and treatment of acute and chronic heart failure 2012: the task force for the diagnosis and treatment of acute and chronic heart failure 2012 of the European Society of Cardiology. Developed in collaboration with the Heart Failure Association (HFA) of the ESC. Eur J Heart Fail. 2012;14:803-69.

4. Jencks SF, Williams MV, Coleman EA. Rehospitalizations among patients in the Medicare Fee-For-Service Program. N Engl J Med. 2009;360:1418-28.

5. Jessup M, Abraham WT, Casey DE, Feldman AM, Francis GS, Ganiats TG, et al. Focused update: ACCF/AHA guidelines for the diagnosis and management of heart failure in adults: a report of the American College of Cardiology Foundation/American Heart Association Task Force on practice guidelines: developed in collaboration with the International Society for Heart and Lung Transplantation. Circulation. 2009;119:1977-2016. doi:10.1161/ CIRCULATIONAHA.109.192064.

6. Lee CS, Tkacs NC, Riegel B. The influence of heart failure selfcare on health outcomes: hypothetical cardioprotective mechanisms. J Cardiovasc Nurs. 2009;24:179-87. doi:10.1097/JCN. 0b013e31819b5419. quiz 188-9.

7. Riegel B, Moser DK, Anker SD, Appel LJ, Dunbar SB, Grady $\mathrm{KL}$, et al. State of the science: promoting self-care in persons with heart failure: a scientific statement from the American Heart Association. Circulation. 2009;120:1141-63. doi:10.1161/ CIRCULATIONAHA.109.192628.

8. Granger BB, Ekman I, Granger CB, Ostergren J, Olofsson B, Michelson E, et al. Adherence to medication according to sex and age in the CHARM programme. Eur J Heart Fail. 2009;11: $1092-8$.

9. van der Wal MH, van Veldhuisen DJ, Veeger NJ, Rutten FH, Jaarsma T. Compliance with non-pharmacological recommendations and outcome in heart failure patients. Eur Heart J. 2010;31: 1486-93.

10. Chin MH, Goldman L. Factors contributing to the hospitalization of patients with congestive heart failure. Am J Public Health. 1997;87:643-8.

11. Riegel B, Jaarsma T, Stromberg A. A middle-range theory of selfcare of chronic illness. ANS Adv Nurs Sci. 2012;35:194-204. doi: 10.1097/ANS.0b013e318261b1ba.

12. Gardetto NJ. Self-management in heart failure: where have we been and where should we go? J Multidiscip Healthc. 2011;4: 39-51.
13. Coleman K, Austin BT, Brach C, Wagner EH. Evidence on the chronic care model in the new millennium. Health Aff (Millwood). 2009;28:75-85. doi:10.1377/hlthaff.28.1.75.

14. Riegel B, Moser DK, Anker SD, Appel LJ, Dunbar SB, Grady $\mathrm{KL}$, et al. State of the science: promoting self-care in persons with heart failure: a scientific statement from the American Heart Association. Circulation. 2009;120:1141-63.

15. Lainscak M, Blue L, Clark AL, Dahlstrom U, Dickstein K, Ekman I, et al. Self-care management of heart failure: practical recommendations from the patient care committee of the heart failure association of the European Society of Cardiology. Eur J Heart Fail. 2011;13:115-26. doi:10.1093/eurjhf/hfq219.

16. Boyde M, Turner C, Thompson DR, Stewart S. Educational interventions for patients with heart failure: a systematic review of randomized controlled trials. J Cardiovasc Nurs. 2011;26:E2735. doi:10.1097/JCN.0b013e3181 ee5fb2.

17. Fredericks S, Beanlands H, Spalding K, Da Silva M. Effects of the characteristics of teaching on the outcomes of heart failure patient education interventions: a systematic review. Eur J Cardiovasc Nurs. 2010;9:30-7. doi:10.1016/j.ejcnurse.2009.08.002.

18. Clark RA, Inglis SC, McAlister FA, Cleland JG, Stewart S. Telemonitoring or structured telephone support programmes for patients with chronic heart failure: systematic review and metaanalysis. BMJ. 2007;334:942.

19. Roccaforte R, Demers C, Baldassarre F, Teo KK, Yusuf S. Effectiveness of comprehensive disease management programmes in improving clinical outcomes in heart failure patients. a meta-analysis. Eur J Heart Fail. 2005;7:1133-44.

20. Gwadry-Sridhar FH, Flintoft V, Lee DS, Lee H, Guyatt GH. A systematic review and meta-analysis of studies comparing readmission rates and mortality rates in patients with heart failure. Arch Intern Med. 2004;164:2315-20.

21. Gonseth J, Guallar-Castillon P, Banegas JR, Rodriguez-Artalejo F. The effectiveness of disease management programmes in reducing hospital re-admission in older patients with heart failure: a systematic review and meta-analysis of published reports. Eur Heart J. 2004;25:1570-95. doi:10.1016/j.ehj.2004.04.022.

22. Gohler A, Januzzi JL, Worrell SS, Osterziel KJ, Gazelle GS, Dietz $\mathrm{R}$, et al. A systematic meta-analysis of the efficacy and heterogeneity of disease management programs in congestive heart failure. J Card Fail. 2006;12:554-67.

23. McAlister FA, Lawson FM, Teo KK, Armstrong PW. A systematic review of randomized trials of disease management programs in heart failure. Am J Med. 2001;110:378-84.

24. Grady KL. Self-care and quality of life outcomes in heart failure patients. J Cardiovasc Nurs. 2008;23:285-92. doi:10.1097/01. JCN.0000305092.42882.ad.

25. Jovicic A, Holroyd-Leduc JM, Straus SE. Effects of selfmanagement intervention on health outcomes of patients with heart failure: a systematic review of randomized controlled trials. BMC Cardiovasc Disord. 2006;6:43.

26. Savard LA, Thompson DR, Clark AM. A meta-review of evidence on heart failure disease management programs: the challenges of describing and synthesizing evidence on complex interventions. Trials. 2011;12:194.

27. Trappenburg J, Jonkman N, Jaarsma T, van Os-Medendorp H, Kort H, de Wit N, et al. Self-management: one size does not fit all. Patient Educ Couns. 2013;92:134-7.

28. Dickson VV, Nocella J, Yoon HW, Hammer M, Melkus GD, Chyun D. Cardiovascular disease self-care interventions. Nurs Res Pract. 2013;2013:407608. doi:10.1155/2013/407608.

29. Curtis LH, Greiner MA, Hammill BG, Kramer JM, Whellan DJ, Schulman KA, et al. Early and long-term outcomes of heart failure in elderly persons, 2001-2005. Arch Intern Med. 2008;168:24818. doi:10.1001/archinte.168.22.2481. 
30. Chriss PM, Sheposh J, Carlson B, Riegel B. Predictors of successful heart failure self-care maintenance in the first three months after hospitalization. Heart Lung. 2004;33:345-53.

31. Cameron J, Worrall-Carter L, Riegel B, Lo SK, Stewart S. Testing a model of patient characteristics, psychologic status, and cognitive function as predictors of self-care in persons with chronic heart failure. Heart Lung. 2009;38:410-8.

32. Riegel B, Vaughan Dickson V, Goldberg LR, Deatrick JA. Factors associated with the development of expertise in heart failure selfcare. Nurs Res. 2007;56:235-43. doi:10.1097/01.NNR. 0000280615.75447.f7.

33.• Jaarsma T, Stromberg A, Ben Gal T, Cameron J, Driscoll A, Duengen HD, et al. Comparison of self-care behaviors of heart failure patients in 15 countries worldwide. Patient Educ Couns. 2013;92:114-20. doi:10.1016/j.pec.2013.02.017. A secondary analysis of data on HF self-care behaviors of patients from 15 countries.

34. Ditewig JB, Blok H, Havers J, van Veenendaal H. Effectiveness of self-management interventions on mortality, hospital readmissions, chronic heart failure hospitalization rate and quality of life in patients with chronic heart failure: a systematic review. Patient Educ Couns. 2010;78:297-315. doi:10.1016/j.pec.2010. 01.016 .

35. Jonkman NH, Westland H, Trappenburg JC, Groenwold RH, Effing-Tijdhof TW, Troosters T, et al. Towards tailoring of selfmanagement for patients with chronic heart failure or chronic obstructive pulmonary disease: A protocol for an individual patient data meta-analysis. BMJ Open. 2014;4: e005220-2014-005220. doi: 10.1136/bmjopen-2014-005220 [doi]. Protocol of a large scale Individual Patient Data Meta-Analysis to unravel effectiveness of self-management in $\mathrm{HF}$ and COPD patients.

36. Kreuter MW, Strecher VJ, Glassman B. One size does not fit all: the case for tailoring print materials. Ann Behav Med. 1999;21: 276-83.

37. Hawkins RP, Kreuter M, Resnicow K, Fishbein M, Dijkstra A. Understanding tailoring in communicating about health. Health Educ Res. 2008;23:454-66.

38. Kreuter MW, Skinner CS. Tailoring: what's in a name? Health Educ Res. 2000;15:1-4.

39. Albert NM, Buchsbaum R, Li J. Randomized study of the effect of video education on heart failure healthcare utilization, symptoms, and self-care behaviors. Patient Educ Couns. 2007;69:129-39.

40. Aldamiz-Echevarria Iraurgui B, Muniz J, Rodriguez-Fernandez JA, Vidan-Martinez L, Silva-Cesar M, Lamelo-Alfonsin F, et al. Randomized controlled clinical trial of a home care unit intervention to reduce readmission and death rates in patients discharged from hospital following admission for heart failure. Rev Esp Cardiol. 2007;60:914-22.

41. Blue L, Lang E, McMurray JJ, Davie AP, McDonagh TA, Murdoch DR, et al. Randomised controlled trial of specialist nurse intervention in heart failure. BMJ. 2001;323:715-8.

42. Bocchi EA, Cruz F, Guimaraes G, Pinho Moreira LF, Issa VS, Ayub Ferreira SM, et al. Long-term prospective, randomized, controlled study using repetitive education at six-month intervals and monitoring for adherence in heart failure outpatients: The REMA DHE trial. Circ Heart Fail. 2008;1:115-24. doi:10.1161/ CIRCHEARTFAILURE.107.744870.

43. Cline CM, Israelsson BY, Willenheimer RB, Broms K, Erhardt LR. Cost effective management programme for heart failure reduces hospitalisation. Heart. 1998;80:442-6.

44. de la Porte PW B-A, Lok DJ, van Wijngaarden J, Cornel JH, Pruijsers-Lamers D, van Veldhuisen DJ, et al. Heart failure programmes in countries with a primary care-based health care system. Are additional trials necessary? Design of the DEAL-HF study. Eur J Heart Fail. 2005;7:910-20.
45. Doughty RN, Wright SP, Pearl A, Walsh HJ, Muncaster S, Whalley GA, et al. Randomized, controlled trial of integrated heart failure management: the Auckland Heart Failure Management Study. Eur Heart J. 2002;23:139-46. doi:10.1053/ euhj.2001.2712.

46.• Heisler M, Halasyamani L, Cowen ME, Davis MD, Resnicow K, Strawderman RL, et al. Randomized controlled effectiveness trial of reciprocal peer support in heart failure. Circ Heart Fail. 2013;6: 246-53. doi:10.1161/CIRCHEARTFAILURE.112.000147. Randomized controlled trial including identification of effect modification.

47. Jaarsma T, van der Wal MH, Lesman-Leegte I, Luttik ML, Hogenhuis J, Veeger NJ, et al. Effect of moderate or intensive disease management program on outcome in patients with heart failure: coordinating study evaluating outcomes of advising and counseling in heart failure $(\mathrm{COACH})$. Arch Intern Med. 2008;168:316-24. doi:10.1001/archinternmed.2007.83.

48. Laramee AS, Levinsky SK, Sargent J, Ross R, Callas P. Case management in a heterogeneous congestive heart failure population: a randomized controlled trial. Arch Intern Med. 2003;163: 809-17. doi:10.1001/archinte.163.7.809.

49. McDonald K, Ledwidge M, Cahill J, Quigley P, Maurer B, Travers B, et al. Heart failure management: multidisciplinary care has intrinsic benefit above the optimization of medical care. J Card Fail. 2002;8:142-8.

50. Powell LH, Calvin Jr JE, Richardson D, Janssen I, de Leon CF M, Flynn KJ, et al. Self-management counseling in patients with heart failure: the heart failure adherence and retention randomized behavioral trial. JAMA. 2010;304:1331-8. doi:10.1001/jama.2010. 1362.

51. Prasun MA, Kocheril AG, Klass PH, Dunlap SH, Piano MR. The effects of a sliding scale diuretic titration protocol in patients with heart failure. J Cardiovasc Nurs. 2005;20:62-70.

52. Ramachandran K, Husain N, Maikhuri R, Seth S, Vij A, Kumar $\mathrm{M}$, et al. Impact of a comprehensive telephone-based disease management programme on quality-of-life in patients with heart failure. Natl Med J India. 2007;20:67-73.

53. Rich MW, Beckham V, Wittenberg C, Leven CL, Freedland KE, Carney RM. A multidisciplinary intervention to prevent the readmission of elderly patients with congestive heart failure. $\mathrm{N}$ Engl J Med. 1995;333:1190-5. doi:10.1056/NEJM199511023331806.

54. Sales VL, Ashraf MS, Lella LK, Huang J, Bhumireddy G, Lefkowitz L, et al. Utilization of trained volunteers decreases 30-day readmissions for heart failure. J Card Fail. 2013;19:84250. doi:10.1016/j.cardfail.2013.10.008.

55. Smith CE, Piamjariyakul U, Wick JA, Spertus JA, Russell C, Dalton KM, et al. Multidisciplinary group clinic appointments: the Self-Management and Care of Heart Failure (SMAC-HF) trial. Circ Heart Fail. 2014;7:888-94. doi:10.1161/ CIRCHEARTFAILURE.113.001246.

56. Martensson J, Stromberg A, Dahlstrom U, Karlsson JE, Fridlund B. Patients with heart failure in primary health care: effects of a nurse-led intervention on health-related quality of life and depression. Eur J Heart Fail. 2005; 7:393-403.

57. Smeulders ES, van Haastregt JC, Ambergen T, Uszko-Lencer NH, Janssen-Boyne JJ, Gorgels AP, et al. Nurse-led self-management group programme for patients with congestive heart failure: randomized controlled trial. J Adv Nurs. 2010;66:1487-99. doi:10. 1111/j.1365-2648.2010.05318.x.

58. Stromberg A, Martensson J, Fridlund B, Levin LA, Karlsson JE, Dahlstrom U. Nurse-led heart failure clinics improve survival and self-care behaviour in patients with heart failure: results from a prospective, randomised trial. Eur Heart J. 2003;24:1014-23.

59. Tsuyuki RT, Fradette M, Johnson JA, Bungard TJ, Eurich DT, Ashton T, et al. A multicenter disease management program for 
hospitalized patients with heart failure. J Card Fail. 2004;10:47380.

60. Varma S, McElnay JC, Hughes CM, Passmore AP, Varma M. Pharmaceutical care of patients with congestive heart failure: interventions and outcomes. Pharmacotherapy. 1999;19:860-9.

61. Wang XH, Qiu JB, Ju Y, Chen GC, Yang JH, Pang JH, et al. Reduction of heart failure rehospitalization using a weight management education intervention. J Cardiovasc Nurs. 2014;29:52834. doi:10.1097/JCN.0000000000000092.

62. Agren S, Evangelista LS, Hjelm C, Stromberg A. Dyads affected by chronic heart failure: a randomized study evaluating effects of education and psychosocial support to patients with heart failure and their partners. J Card Fail. 2012;18:359-66. doi:10.1016/j. cardfail.2012.01.014

63.•• DeWalt DA, Schillinger D, Ruo B, Bibbins-Domingo K, Baker DW, Holmes GM, et al. Multisite randomized trial of a singlesession versus multisession literacy-sensitive self-care intervention for patients with heart failure. Circulation. 2012;125:2854 62. doi:10.1161/CIRCULATIONAHA.111.081745. Randomized controlled trial including identification of effect modification.

64. Dickson VV, Melkus GD, Katz S, Levine-Wong A, Dillworth J, Cleland CM, et al. Building skill in heart failure self-care among community dwelling older adults: results of a pilot study. Patient Educ Couns. 2014;96:188-96. doi:10.1016/j.pec.2014.04.018.

65. Riegel B, Carlson B. Is individual peer support a promising intervention for persons with heart failure? J Cardiovasc Nurs. 2004;19:174-83.

66. Riegel B, Carlson B, Glaser D, Romero T. Randomized controlled trial of telephone case management in Hispanics of Mexican origin with heart failure. J Card Fail. 2006;12:211-9.

67. Barnason S, Zimmerman L, Hertzog M, Schulz P. Pilot testing of a medication self-management transition intervention for heart failure patients. West J Nurs Res. 2010;32:849-70. doi:10.1177/ 0193945910371216.

68. Clark AP, McDougall G, Riegel B, Joiner-Rogers G, Innerarity S, Meraviglia M, et al. Health status and self-care outcomes after an education-support intervention for people with chronic heart failure. J Cardiovasc Nurs. 2014. doi:10.1097/JCN. 0000000000000169 .

69. Dunagan WC, Littenberg B, Ewald GA, Jones CA, Emery VB, Waterman BM, et al. Randomized trial of a nurse-administered, telephone-based disease management program for patients with heart failure. J Card Fail. 2005;11:358-65.

70. Ekman I, Andersson B, Ehnfors M, Matejka G, Persson B, Fagerberg B. Feasibility of a nurse-monitored, outpatient-care programme for elderly patients with moderate-to-severe, chronic heart failure. Eur Heart J. 1998;19:1254-60.

71. Riegel B, Carlson B, Kopp Z, LePetri B, Glaser D, Unger A. Effect of a standardized nurse case-management telephone intervention on resource use in patients with chronic heart failure. Arch Intern Med. 2002;162:705-12.

72. Angermann CE, Stork S, Gelbrich G, Faller H, Jahns R, Frantz S, et al. Mode of action and effects of standardized collaborative disease management on mortality and morbidity in patients with systolic heart failure: the interdisciplinary network for heart failure (INH) study. Circ Heart Fail. 2012;5:25-35. doi:10.1161/ CIRCHEARTFAILURE.111.962969.

73. Peters-Klimm F, Campbell S, Hermann K, Kunz CU, MullerTasch T, Szecsenyi J, et al. Case management for patients with chronic systolic heart failure in primary care: The HICMan exploratory randomised controlled trial. Trials. 2010;11: 56-621511-56. doi: 10.1186/1745-6215-11-56 [doi].

74. Davis KK, Mintzer M, Dennison Himmelfarb CR, Hayat MJ, Rotman S, Allen J. Targeted intervention improves knowledge but not self-care or readmissions in heart failure patients with mild cognitive impairment. Eur J Heart Fail. 2012;14:1041-9. doi:10. 1093/eurjhf/hfs096.

75. DeWalt DA, Malone RM, Bryant ME, Kosnar MC, Corr KE, Rothman RL, et al. A heart failure self-management program for patients of all literacy levels: a randomized, controlled trial [ISRCTN11535170. BMC Health Serv Res. 2006;6:30.

76. Bandura A. Self-efficacy: toward a unifying theory of behavioral change. Psychol Rev. 1977;84:191-215.

77.• Shively MJ, Gardetto NJ, Kodiath MF, Kelly A, Smith TL, Stepnowsky C, et al. Effect of patient activation on selfmanagement in patients with heart failure. J Cardiovasc Nurs. 2013;28:20-34. doi:10.1097/JCN.0b013e318239f9f9.

Randomized controlled trial including identification of effect modification.

78. Connelly CE. An empirical study of a model of self-care in chronic illness. Clin Nurse Spec. 1993;7:247-53.

79. Rockwell JM, Riegel B. Predictors of self-care in persons with heart failure. Heart Lung. 2001;30:18-25.

80. Holzapfel N, Lowe B, Wild B, Schellberg D, Zugck C, Remppis A, et al. Self-care and depression in patients with chronic heart failure. Heart Lung. 2009;38:392-7. doi:10.1016/j.hrtlng.2008. 11.001

81. Fan X, Lv F. Psychosocial factors associated with self-efficacy for managing chronic disease in patients with chronic heart failure. Eur J Cardiovasc Nurs. 2014. doi: 1474515114566157 [pii].

82. Moser DK, Doering LV, Chung ML. Vulnerabilities of patients recovering from an exacerbation of chronic heart failure. Am Heart J. 2005;150:984.

83. Cocchieri A, Riegel B, D'Agostino F, Rocco G, Fida R, Alvaro R, et al. Describing self-care in italian adults with heart failure and identifying determinants of poor self-care. Eur J Cardiovasc Nurs. 2014. doi: 1474515113518443 [pii].

84. Cameron J, Worrall-Carter L, Page K, Stewart S. Self-care behaviours and heart failure: does experience with symptoms really make a difference? Eur J Cardiovasc Nurs. 2010;9:92-100. doi: 10.1016/j.ejcnurse.2009.10.004.

85. Riegel B, Carlson B, Moser DK, Sebern M, Hicks FD, Roland V. Psychometric testing of the self-care of heart failure index. J Card Fail. 2004;10:350-60.

86. Evangelista LS, Rasmusson KD, Laramee AS, Barr J, Ammon SE, Dunbar S, et al. Health literacy and the patient with heart failure - implications for patient care and research: a consensus statement of the Heart Failure Society of America. J Card Fail. 2010;16:9-16. doi:10.1016/j.cardfail.2009.10.026.

87. Chen AM, Yehle KS, Plake KS, Murawski MM, Mason HL. Health literacy and self-care of patients with heart failure. J Cardiovasc Nurs. 2011;26:446-51. doi:10.1097/JCN. 0b013e31820598d4.

88. Macabasco-O'Connell A, DeWalt DA, Broucksou KA, Hawk V, Baker DW, Schillinger D, et al. Relationship between literacy, knowledge, self-care behaviors, and heart failure-related quality of life among patients with heart failure. J Gen Intern Med. 2011;26:979-86. doi:10.1007/s11606-011-1668-y.

89. Dennison CR, McEntee ML, Samuel L, Johnson BJ, Rotman S, Kielty A, et al. Adequate health literacy is associated with higher heart failure knowledge and self-care confidence in hospitalized patients. J Cardiovasc Nurs. 2011;26:359-67. doi:10.1097/JCN. 0b013e3181f16f88.

90. Siabani S, Leeder SR, Davidson PM. Barriers and facilitators to self-care in chronic heart failure: a meta-synthesis of qualitative studies. Springerplus. 2013;2:320. A meta-synthesis including many qualitative studies aimed at increasing our understanding on varying self-management capacity.

91. Strachan PH, Currie K, Harkness K, Spaling M, Clark AM. Context matters in heart failure self-care: a qualitative systematic review. J Card Fail. 2014;20:448-55. doi:10.1016/j.cardfail.2014. 
03.010. A meta-synthesis including many qualitative studies aimed at increasing our understanding on varying selfmanagement capacity.

92. Kraemer HC, Frank E, Kupfer DJ. Moderators of treatment outcomes: clinical, research, and policy importance. JAMA. 2006;296:1286-9.

93. Greenfield S, Kravitz R, Duan N, Kaplan SH. Heterogeneity of treatment effects: implications for guidelines, payment, and quality assessment. Am J Med. 2007;120:S3-9.

94. Grobbee DE, Hoes AW. Clinical epidemiology: principles, methods, and applications for clinical research. Boston: Jones and Bartlett; 2009.

95. Rothman KJ, Greenland S. Modern epidemiology. 2nd ed. Philadelphia: Lippincott-Raven; 1998.

96.• Grady KL, de Leon CF, Kozak AT, Cursio JF, Richardson D, Avery E, et al. Does self-management counseling in patients with heart failure improve quality of life? Findings from the heart failure adherence and retention trial (HART). Qual Life Res. 2014;23: 31-8. doi:10.1007/s11136-013-0432-7. Secondary analysis of a randomized controlled trial including identification of effect modification.

97. Holst M, Willenheimer R, Martensson J, Lindholm M, Stromberg A. Telephone follow-up of self-care behaviour after a single session education of patients with heart failure in primary health care. Eur J Cardiovasc Nurs. 2007;6:153-9.

98. Smeulders ES, van Haastregt JC, Ambergen T, Stoffers HE, Janssen-Boyne JJ, Uszko-Lencer NH, et al. Heart failure patients with a lower educational level and better cognitive status benefit most from a self-management group programme. Patient Educ Couns. 2010;81:214-21. doi:10.1016/j.pec.2010.01.003.

99. Baker DW, Dewalt DA, Schillinger D, Hawk V, Ruo B, BibbinsDomingo K, et al. The effect of progressive, reinforcing telephone education and counseling versus brief educational intervention on knowledge, self-care behaviors and heart failure symptoms. J Card Fail. 2011;17:789-96. doi:10.1016/j.cardfail.2011.06.374.

100. Jaarsma T, Lesman-Leegte I, Hillege HL, Veeger NJ, Sanderman $\mathrm{R}$, van Veldhuisen DJ, et al. Depression and the usefulness of a disease management program in heart failure: insights from the $\mathrm{COACH}$ (coordinating study evaluating outcomes of advising and counseling in heart failure) study. J Am Coll Cardiol. 2010;55: 1837-43. doi:10.1016/j.jacc.2009.11.082.

101. Weiss BD. Health literacy and patient safety: help patients understand: a manual for clinicians. 2nd ed. . 2007.

102. van der Wal MH, Jaarsma T, van Voorst R. Psychiatric nurse; member of the HF management team? Eur J Cardiovasc Nurs. 2005;4:99-100.

103. Michie S, Richardson M, Johnston M, Abraham C, Francis J, Hardeman W, et al. The behavior change technique taxonomy (v1) of 93 hierarchically clustered techniques: building an international consensus for the reporting of behavior change interventions. Ann Behav Med. 2013;46:81-95. doi:10.1007/s12160-0139486-6.

104. Murphy SA. An experimental design for the development of adaptive treatment strategies. Stat Med. 2005;24:1455-81. doi:10. 1002/sim.2022.

105. Lei H, Nahum-Shani I, Lynch K, Oslin D, Murphy SA. A "SMART" design for building individualized treatment sequences. Annu Rev Clin Psychol. 2012;8:21-48. doi:10.1146/ annurev-clinpsy-032511-143152.
106. Atienza F, Anguita M, Martinez-Alzamora N, Osca J, Ojeda S, Almenar L, et al. Multicenter randomized trial of a comprehensive hospital discharge and outpatient heart failure management program. Eur J Heart Fail. 2004;6:643-52. doi:10.1016/j.ejheart. 2003.11.023.

107. Cockayne S, Pattenden J, Worthy G, Richardson G, Lewin R. Nurse facilitated self-management support for people with heart failure and their family carers (SEMAPHFOR): a randomised controlled trial. Int J Nurs Stud. 2014;51:1207-13. doi:10.1016/ j.ijnurstu.2014.01.010.

108. Dracup K, Moser DK, Pelter MM, Nesbitt TS, Southard J, Paul $\mathrm{SM}$, et al. Randomized, controlled trial to improve self-care in patients with heart failure living in rural areas. Circulation. 2014;130:256-64. doi:10.1161/CIRCULATIONAHA.113. 003542 .

109. Dunbar SB, Clark PC, Reilly CM, Gary RA, Smith A, McCarty F, et al. A trial of family partnership and education interventions in heart failure. J Card Fail. 2013;19:829-41. doi:10.1016/j.cardfail. 2013.10.007.

110. Jurgens CY, Lee CS, Reitano JM, Riegel B. Heart failure symptom monitoring and response training. Heart Lung. 2013;42:273-80. doi:10.1016/j.hrtlng.2013.03.005.

111. Leventhal ME, Denhaerynck K, Brunner-La Rocca HP, Burnand $\mathrm{B}$, Conca-Zeller A, Bernasconi AT, et al. Swiss interdisciplinary management programme for heart failure (SWIM-HF): a randomised controlled trial study of an outpatient interprofessional management programme for heart failure patients in Switzerland. Swiss Med Wkly. 2011;141:w13171. doi:10.4414/ smw.2011.13171.

112. Jaarsma T, Halfens R, Huijer Abu-Saad H, Dracup K, Gorgels T, van Ree J, et al. Effects of education and support on self-care and resource utilization in patients with heart failure. Eur Heart J. 1999;20:673-82. doi:10.1053/euhj.1998.1341.

113. Otsu H, Moriyama M. Effectiveness of an educational selfmanagement program for outpatients with chronic heart failure. Jpn J Nurs Sci. 2011;8:140-52. doi:10.1111/j.1742-7924.2010. 00166.x.

114. Shao JH, Chang AM, Edwards H, Shyu YI, Chen SH. A randomized controlled trial of self-management programme improves health-related outcomes of older people with heart failure. J Adv Nurs. 2013;69:2458-69. doi:10.1111/jan.12121.

115. Shearer NB, Cisar N, Greenberg EA. A telephone-delivered empowerment intervention with patients diagnosed with heart failure. Heart Lung. 2007;36:159-69.

116. Shively M, Kodiath M, Smith TL, Kelly A, Bone P, Fetterly L, et al. Effect of behavioral management on quality of life in mild heart failure: a randomized controlled trial. Patient Educ Couns. 2005;58:27-34.

117. Sisk JE, Hebert PL, Horowitz CR, McLaughlin MA, Wang JJ, Chassin MR. Effects of nurse management on the quality of heart failure care in minority communities: a randomized trial. Ann Intern Med. 2006;145:273-83.

118. Wakefield BJ, Ward MM, Holman JE, Ray A, Scherubel M, Burns TL, et al. Evaluation of home telehealth following hospitalization for heart failure: a randomized trial. Telemed J E Health. 2008;14: 753-61. doi:10.1089/tmj.2007.0131.

119. Wongpiriyayothar A, Pothiban L, Liehr P, Senaratana W. Effects of a home-based care program on symptom alleviation and wellbeing among persons with chronic heart failure. Thai J Nurse Res. 2008;12:25-39. 